\title{
Food science without borders
}

\author{
Dietrich Knorr ${ }^{1 *}$ and Chor San H. Khoo ${ }^{2}$ \\ ${ }^{1}$ Department of Food Biotechnology and Food Process Engineering, Technische Universität Berlin, Berlin, Germany, ${ }^{2}$ North \\ American Branch of the International Life Sciences Institute, Washington, DC, USA
}

Keywords: food science, nutritional sciences, global food challenges, food chain integration, interdisciplinary research, transdisciplinary research, systems approach

The recent 25th anniversary of the fall of the Berlin Wall serves to remind us that sometimes "falling walls" are needed to solve differences not only between nations but also among the different disciplines of science. This need is underscored by a recent paradigm shift in research approaches to address multilayer and multistage research problems. This shift has seen a gradual transition from a "reductionist" approach to a more encompassing "total systems" approach in problem solving. One such approach is transdisciplinary research. Transdisciplinary research is currently widely used in biomedical and health programs and is gaining popularity in other areas as well, including climate change and environmental impact, food security, and sustainability (1-3).

Unfortunately, within biomedical research, the involvement of food and nutrition sciences is underemphasized in the transdisciplinary research equation. As a result, food and nutritional impact and its importance in health and disease management are understudied and under-recognized. This lack of representation can have long-term consequential effects for food research, impacting research funding, student recruitment and training grants, publication interest, impact realization,

OPEN ACCESS

Edited by:

Marco Dalla Rosa,

Alma Mater Studiorum University of

Bologna, Italy

Reviewed by:

Jesus Maria Frias Celayeta,

Dublin Institute of Technology, Ireland

Mona Elena Popa,

University of Agronomic Sciences and

Veterinary Medicine, Romania

${ }^{*}$ Correspondence:

Dietrich Knorr

dietrich.knorr@tu-berlin.de

Specialty section:

This article was submitted to Nutrition and Food Science Technology, a section of the

journal Frontiers in Nutrition

Received: 13 April 2015 Accepted: 09 October 2015 Published: 22 October 2015

Citation:

Knorr D and Khoo CSH (2015)

Food science without borders.

Front. Nutr. 2:33.

doi: 10.3389/fnut.2015.00033 and prioritization (4).

For investigators in the food science, this trend is worrisome, as exemplified by the current emphasis on the impact and h-index factors to evaluate scientific performance, advancements, and funding. Areas that have been involved in biomedical and medical engineering with a health and disease focus (e.g., chemistry, biology, engineering, and medicine) have received increased funding attention, prioritization, and resources. This has led to a surge in researchers entering these research fields. In addition, it has also increased interest by research journals to publish in these areas.

Food and diet studies are complex and involve several scientific disciplines. Within the foodrelated fields, there are food technologists, food engineers, chemists, microbiologists, psychologists, psychophysiologists, biochemists, biologists, statisticians, sensory physiologists, toxicologists, nutritionists, and biotechnologists. Many food researchers have different societal affiliations, publication interest and limited interaction with each other. Matters are more complex in the nutrition fields, with different training emphasis among the various groups - nutrition science, dietetics, medicine, nutrition biochemistry.

Food research is often misunderstood as "soft" research, focusing primarily on technology development and application. On the contrary, many areas in food research (e.g., food safety and product efficacy, impact on health outcomes) require both basic and applied sciences. This knowledge is not widely known, and it is the only contributing reason why the food science discipline is often not included in biomedical research. In an example related to a national research grant review session, reviewers with medical backgrounds tended to underrate the scientific and research capability of food and nutritional experts or food engineers because of a perceived misconception that these scientists lack sufficient experience and participation in research projects or publication in high-impact journals.

There are other instances in which recognition of food science as a "hard" science has been under-recognized, despite the tremendous responsibilities and challenges to the field to provide safe, healthy, sustainable, and functional food, as well as safe drinking water and nutrition security to every human being. With the world's population increasing from currently 7 to 9.6 billion by 
2050 (5), there are tremendous challenges ahead. Some of the challenges include the emergence of new pathogens, an increasing aging population, the obesity pandemic, climate change, food and nutrient losses and waste, and hunger (6). Solving these issues require the collective attention of all related disciplines along the food chain. This calls for a need to take down the interdisciplinary walls among scientists and to work closely on productive solutions to achieve food and nutrition security (7).

At a workshop of the 2014 World Congress of the International Union of Food Science and Technology, young investigators of food science identified the critical need for increased communication among scientists, policymakers, governments, nongovernmental organizations, and consumers (8). It is crucial to follow such suggestions from the future leaders in food science. In addition, the involvement of international public and private funding bodies is also critical.

One encouraging example of how multidisciplinary cooperation has worked is the European Union-founded Cooperation in Science and Technology (COST) project on electroporation-based technologies and treatments (9), in which electrical engineers, food scientists, and physicians have shared expertise and experience by interacting with each other in an open and respectful manner. As a result, pulsed electric field technologies and other high hydrostatic pressure technologies and equipment, developed by food scientists and engineers, are now being applied in medicine, cosmetics, pharmacy, and biotechnology $(10,11)$.

Interestingly, in 2014, Sharp pointed out that "Physicists gave engineers the electron and they created the IT revolution. Biologists gave engineers the gene and together they will create the

\section{REFERENCES}

1. Klein J. Evaluation of interdisciplinary and transdisciplinary research - a literature review. Am J Prev Med (2008) 35(2 Suppl):116-23. doi:10.1016/j.amepre. 2008.05.010

2. Hammond R, Dubé L. A system science perspective and transdisciplinary models for food and nutrition security. Proc Natl Acad Sci U S A (2012) 109(31):12356-65. doi:10.1073/pnas.0913003109

3. Auestad N, Fulgoni V III. What current literature tells us about sustainable diets: emerging research linking dietary patterns, environmental sustainability, and economics. Adv Nutr (2015) 6:19-36. doi:10.3945/an.114. 005694

4. Holmes JH, Lehman A, Hade E, Ferketich AK, Gehlert S, Rauscher GH, et al. Challenges for multilevel health disparities research in a transdisciplinary environment. Am J Prev Med (2008) 35(2 Suppl):182-92. doi:10.1016/j.amepre. 2008.05.019

5. Census Bureau. International Programs. International Data Base, World Population: 1950-2050 (2015). Available from: http://www.census.gov

6. Godfray HC, Beddington JR, Crute IR, Haddad L, Lawrence D, Muir JF, et al. Food security: the challenge of feeding 9 billion people. Science (2010) 327(5967):812-8. doi:10.1126/science.1185383

7. Sepulveda J, Murray C. The state of global health in 2014. Science (2014) 345(6202):1218-75. doi:10.1126/science.1257099

8. International Union of Food Science and Technology. IUFoST Website (2014). Available from: http://www.iufost.org

9. European Cooperation in Science and Technology. Electroporation-Based Technologies (2014). Available from: http://www.ebtt.org

10. Rivalain N, Roquain J, Demazeau G. Development of high hydrostatic pressure in biosciences: pressure effect on biological structures and potential applications in biotechnologies. Biotechnol Adv (2010) 28(6):659-72. doi:10.1016/j. biotechadv.2010.04.001 future. Perhaps when the biologists give the genes to the food scientists and engineers together they can create sustainable foods and precision diets for individual longevity" (12).

There are many emerging research areas in which transdisciplinary research approaches may shift the existing paradigm. For example, there has been a resurgence of interest in the microbiome and health. Although food scientists have worked in this area for more than 100 years, as evidenced by the high number of related dairy products in the marketplace today, understanding of microbial-host interactions, modes of action, and mechanistic pathways in disease ecology and treatment can best be achieved through multidisciplinary approaches (13-18). Another example is the current need for new and additional sources of food raw materials, such as work on insects and insect proteins $(19,20)$ and exploration of marine chitin, the second most abundant organic compound on earth (21), for food, biologics, medicine, and pharmaceutical agents (22).

In addition, the development of new technologies, such as pulsed electric fields (23), will allow for the development of more effective permeable biological membranes and will enable researchers to take advantage of the vast amount of existing but mainly forgotten expertise and product developments in the fields of single-cell proteins (24) as well as plant protein concentrates (25-27).

What is evident is that with limitations in funding resources, it is important to work toward a future agenda in which transdisciplinary research becomes the norm and food science is better integrated in biomedical research. Food science research without borders is critically needed now!

11. Hiperbaric. High Pressure Processing for Food \& Beverage Products (2014) Available from: http://www.hiperbaric.com

12. Sharp PA. Meeting global challenges: discovery and innovation through convergence. Science (2014) 346(6216):1468-71. doi:10.1126/science.aaa3192

13. Metchnikoff E. The Prolongation of Life; Optimistic Studies. New York, NY; London: G.P. Putnam's Sons (1908)

14. Ananta E, Birkeland SE, Corcoran B, Fitzgerald G, Hinz S, Klijn A, et al. Processing effects on the nutritional advancement of probiotics and prebiotics. Microb Ecol Health Dis (2004) 16(2-3):113-24. doi:10.1080/08910600410032277

15. Belkaid Y, Segre JA. Dialogue between skin microbiota and immunity. Science (2014) 346(6212):954-9. doi:10.1126/science.1260144

16. Lahti L, Salojärvi J, Salonen A, Scheffer M, de Vos W. Tipping elements in the human intestinal ecosystem. Nat Commun (2014) 5:4344. doi:10.1038/ ncomms5344

17. Mekkes MC, Weenen TC, Brummer RJ, Claassen E. The development of probiotic treatment in obesity: a review. Benef Microbes (2014) 5(1):19-28. doi:10.3920/BM2012.0069

18. Salonen A, Lahti L, Salojärvi J, Holtrop G, Korpela K, Duncan SH, et al. Impact of diet and individual variation on intestinal microbiota composition and fermentation products in obese men. ISME J (2014) 8(11):2218-30. doi:10. 1038/ismej.2014.63

19. Van Huis A, Van Itterbeeck J, Klunder H, Mertens E, Halloran A, Muir G, et al. Edible Insects - Future Prospects for Food and Feed Security. Rome: Food and Agriculture Organization of the United Nations (2013).

20. Rumpold BA, Fröhling A, Reineke K, Knorr D, Boguslawski S, Ehlbeck J, et al. Comparison of volumetric and surface decontamination techniques for innovative processing of mealworm larvae (Tenebrio molitor). Innov Food Sci Emerg Technol (2014) 26:232-41. doi:10.1016/j.ifset.2014.09.002

21. Muzzarelli RAA. Chitin. Oxford: Pergamon Press (1977).

22. Kim SK. Marine Carbohydrates: Fundamentals and Applications, Part B. London: Academic Press (2014). 
23. Raso J, Heinz V. Pulsed Electric Fields Technology for the Food Industry. New York, NY: Springer (2006).

24. Knorr D, Shetty KJ, Hood LF, Kinsella JE. Enzymatic method for yeast autolysis. J Food Sci (1979) 44(5):1362-5. doi:10.1111/j.1365-2621.1979. tb06439.x

25. Pirie NW. Leaf Protein: Its Agronomy, Preparation, Quality and Use. London: International Biological Programme (1971).

26. Knuckles B, Bickoff E, Kohler G. PRO-XAN process: methods for increasing protein recovery from alfalfa. J Agric Food Chem (1972) 20(5):1055-7. doi:10. 1021/jf60183a020

27. Wang J, Kinsella JE. Composition of alfalfa leaf protein isolates. J Food Sci (1975) 40(6):1156-61. doi:10.1111/j.1365-2621.1975.tb01041.x
Disclaimer: The opinions expressed are those of the authors and may not reflect those of their affiliated organizations.

Conflict of Interest Statement: The authors declare that the research was conducted in the absence of any commercial or financial relationships that could be construed as a potential conflict of interest.

Copyright $\odot 2015$ Knorr and Khoo. This is an open-access article distributed under the terms of the Creative Commons Attribution License (CC BY). The use, distribution or reproduction in other forums is permitted, provided the original author(s) or licensor are credited and that the original publication in this journal is cited, in accordance with accepted academic practice. No use, distribution or reproduction is permitted which does not comply with these terms. 